\title{
Discrete Approximate Solution of Differential Inclusion with Normal Cone and Prox-Regular Set.
}

\section{Abdallah Beddani ( $\sim$ beddani2016@gmail.com )}

Centre Universitaire de Relizane https://orcid.org/0000-0002-8800-1088

\section{Rahma Sahraoui}

Université Abdelhamid Ibn Badis de Mostaganem: Universite Abdelhamid Ibn Badis de Mostaganem

\section{Research Article}

Keywords: Differential inclusion, Discret solution, Prox-regular, Normal cone, Nonsmooth analysis

Posted Date: January 12th, 2022

DOI: https://doi.org/10.21203/rs.3.rs-943478/v1

License: (c) (1) This work is licensed under a Creative Commons Attribution 4.0 International License. Read Full License 


\title{
An approximate solution of differential inclusion with prox-regular set
}

\author{
A. Beddani ${ }^{1,2}$ and R. Sahraoui ${ }^{1,3}$ \\ ${ }^{1}$ Laboratory of Fundamental and Applied Mathematics of Oran \\ (LMFAO), University of Oran 1, Ahmed BENBELLA. \\ ${ }^{2}$ Relizane University, Bourmadia, Relizane, Algeria, 48000. \\ ${ }^{3}$ E.S.A. Mostaganem Algeria, 27000.
}

Contributing authors: beddani2016@gmail.com; sahraourah68@gmail.com;

\begin{abstract}
The aim of this paper is to calculate the approximate solution of differential inclusion with prox-regular set, the question is how to calculate this solution? We use the discrete approximation property of a new variant of nonconvex sweeping processes involving normal cone and a finite element method. Knowing that the majority of mathematicians have proved only the existence and uniqueness of the solution for this type of inclusions, like: Mordukhovich, Thibault, Aubin, Messaoud,...etc.
\end{abstract}

Keywords: Differential inclusion, Discret solution, Prox-regular, Normal cone, Nonsmooth analysis.

MSC Classification: 34A60 , 49J52, 37B25. 
Differential inclusion with prox-regular set

\section{Introduction}

The domain of differential inclusions plays a major role in finding solutions to some physical problems see, [1],[2],[21],[23],[8],[10]. In our work, we will present a numerical method for calculating the approximate solution of a differential inclusion with normal cone for prox-regular sets, this problem has been studied extensively see, [18],[19],[17], for existence and uniqueness of the solutions see, $[11],[12],[3],[9]$ and also gave some properties and theories that help us reach the proof of the proposed convergence on our side. We use also the same method (Discrete approximation solution), see, [14],[15], [7],[22],[20],[4], knowing that these methods were applied to the differential inclusion $\dot{x}(t) \in F(x(t))$ a.e $t \in[0, T], x(0)=x_{0}$ that was studied by Mordukhovich, see, [13] and also applied to the differential inclusion $\dot{x}(t) \in-\mathrm{N}_{C}(x(t))$ a.e $t \in[0, T], x(0)=x_{0}$ see, [16]. In this paper we will study the following problem.

$$
\left\{\begin{array}{l}
\dot{x}(t) \in f(x(t))-\mathrm{N}_{C}(x(t)) \text { a.e } t \in[0,1] \\
x(0)=x_{0} \in C
\end{array}\right.
$$

for all absolutely continuous $x:[0,1] \rightarrow \mathbb{R}^{N}$. Where $C$ is a nonempty closed $r$-prox-regular subset of $\mathbb{R}^{n},(r>0), \mathrm{N}_{C}(x)$ is the normal cone to $C$ at $x \in C$, and $f: \mathbb{R}^{N} \rightarrow \mathbb{R}^{N}$ be a Lipschitz function and bounded in $C$. Then, there is $M>0$ such that

$$
\|f(x)\| \leq M, \forall x \in C+r \mathbb{B} .
$$

The existence and uniqueness of solutions of (1.1) is proved in [11] by L. Thibault and J. F. Edmond, but he had not calculate this solution.

So, for this raison we consider the discrete approximations

$$
\left\{\begin{array}{l}
\dot{x}_{n}\left(t_{j}\right) \in f\left(x_{n}\left(t_{j}\right)\right)+n\left(x_{n}\left(t_{j}\right)-P_{C}\left(x_{n}\left(t_{j}\right)\right)\right), j=0, \ldots, n \\
x_{n}(0)=x_{0} \in C
\end{array}\right.
$$

where:

1) $P_{C}(s)=\left\{h \in C:\|s-h\|=\inf _{y \in C}\|s-y\|\right\}$,

2) $t_{j}:=j h_{n}, j=0, \ldots, n, h_{n}=\frac{1}{n}$,

3) $\dot{x}_{n}\left(t_{j}\right)=\frac{x_{n}\left(t_{j+1}\right)-x_{n}\left(t_{j}\right)}{h_{n}}, j=0, \ldots, n$,

4) $\dot{x}_{n}(t)=\dot{x}_{n}\left(t_{j}\right), \forall t \in\left[t_{j}, t_{j+1}[, j=0, \ldots, n\right.$

5) $x_{n}(t)=x_{n}\left(t_{j}\right)-\left(t-t_{j}\right) \dot{x}_{n}\left(t_{j}\right), \forall t \in\left[t_{j}, t_{j+1}[, j=0, \ldots, n\right.$.

Similarly observe that the discrete-time inclusions(1.3) is equivalent to

$$
\left\{\begin{array}{l}
x_{n}\left(t_{j+1}\right) \in \frac{1}{n} f\left(x_{n}\left(t_{j}\right)\right)+P_{C}\left(x_{n}\left(t_{j}\right)\right), j=0, \ldots, n-1, \\
x_{n}(0)=x_{0}
\end{array}\right.
$$

Our idea is to prove that, if $x_{n}(\cdot)$ being the piecewise extension of the unique discrete trajectory $x_{n}\left(t_{j}\right), j=0, \ldots, n$ is a solution of $(1.3)$ and if $x(\cdot)$ is a 
solution of $(1.1)$, we have $x_{n}(\cdot)$ converges uniformly to $x(\cdot)$ as $n \rightarrow+\infty$, and there exist a subsequence $\dot{x}_{n_{k}}(\cdot) \rightarrow \dot{x}(\cdot)$ as $n \rightarrow+\infty$ weakly in $L^{2}\left([0,1], \mathbb{R}^{N}\right)$, and for each $j=0, \cdots, n, x_{n}\left(t_{j}\right) \in C+\frac{M}{n} \mathbb{B}$, has a unique projection on $C$. Moreover, the piecewise extension $x_{n}(\cdot)$ of the discrete trajectory $x_{n}\left(t_{j}\right)$, $j=0, \cdots, n$, also satisfies $x_{n}(t) \in C+\frac{M}{n} \mathbb{B}$ a.e $t \in[0,1]$, where $\mathbb{B}$ the unit ball in $\mathbb{R}^{N}$.

\section{Definitions and Notations}

The following definitions are quite standard. We can refer to [8],[17] for further details. First, we will give some notations used in this paper. The distance function to a closed set $S$ is given by $d_{S}(x):=\inf _{y \in S}\|x-y\|$.

Let $C$ be a nonempty subset of $\mathbb{R}^{N}, \bar{C}$ the closure of $\mathrm{C}, \overline{c o}(C)$ the closed convex cone of $\mathrm{C}$.

\subsection{Clarke tangent cone}

1) Let $x \in \bar{C}$. We say that $h \in \mathbb{R}^{N}$ is a tangent vector to $C$ at $x$, if, $\forall x_{n} \in C, \forall \lambda_{n} \in \mathbb{R}^{+}, \exists h_{n} \in \mathbb{R}^{N}, \forall n \in \mathbb{N}$ with $x=\lim _{n \rightarrow+\infty} x_{n}, \lim _{n \rightarrow+\infty} \lambda_{n}=0$, $h=\lim _{n \rightarrow+\infty} h_{n}$ and $x_{n}-\lambda_{n} h_{n} \in C, \forall n \in \mathbb{N}$.

2) $T_{C l}(C, x)=\left\{\begin{array}{c}h \in \mathbb{R}^{N} / \forall x_{n} \in C, \forall \lambda_{n} \in \mathbb{R}^{+}, \exists h_{n} \in \mathbb{R}^{N} \text { with } \lim _{n \rightarrow+\infty} x_{n}=x, \\ \lim _{n \rightarrow+\infty} \lambda_{n}=0, \lim _{n \rightarrow+\infty} h_{n}=h \text { and } x_{n}-\lambda_{n} h_{n} \in C, \forall n \in \mathbb{N}\end{array}\right\}$ The set $T_{C l}(C, x)$ is called (sequential) Clarke tangent cone to $C$ at $x$. 3) We define by $\mathrm{N}_{C l}(C, x)=\left\{h \in \mathbb{R}^{N} /\langle h, v\rangle \leq 0, \forall v \in T_{C l}(C, x)\right\}$ the normal cone of Clarke to $C$ at $x$.

\subsection{Bouligand tangent cone}

1) Let $x \in \bar{C}$. We say that $h \in \mathbb{R}^{N}$ is a tangent vector to $C$ at $x$, if, $\exists x_{n} \in$ $C, \exists \lambda_{n} \in \mathbb{R}^{+}, \forall n \in \mathbb{N}$ with $x=\lim _{n \rightarrow+\infty} x_{n}, \lim _{n \rightarrow+\infty} \lambda_{n}=0$ and $h=\lim _{n \rightarrow+\infty} \frac{x_{n}-x}{\lambda_{n}}$. 2) $T(C, x)=\left\{\begin{array}{c}h \in \mathbb{R}^{N} / \exists x_{n} \in C, \exists \lambda_{n} \in \mathbb{R}^{+} \text {with } x=\lim _{n \rightarrow+\infty} x_{n}, \\ \lim _{n \rightarrow+\infty} \lambda_{n}=0 \text { and } h=\lim _{n \rightarrow+\infty} \frac{x_{n}-x}{\lambda_{n}}\end{array}\right\}$.

The set $T(C, x)$ ou $T_{C}(x)$ is called Bouligand tangent cone to $C$ at $x$.

3) We define by $\mathrm{N}_{C}(x)=\left\{h \in \mathbb{R}^{N} /\langle h, v\rangle \leq 0, \forall v \in T(C, x)\right\}$ the normal cone to $C$ at $x$.

Proposition 2.1. $T_{C l}(C, x) \subset T_{C}(x)$ and $\mathrm{N}_{C}(x) \subset \mathrm{N}_{C l}(C, x)$. 
Differential inclusion with prox-regular set

\subsection{Prox-regular set}

Let $C \subset \mathbb{R}^{N}$ be a closed subset, $x \in C$ and $\left.\left.r \in\right] 0,+\infty\right]$.

We define by $N^{P}(C, x):=\left\{v \in X: \exists r>0, x \in P_{C}(x+r v)\right\}$

the proximal normal cone to $C$ at $x$.

Definition 2.2. The set $C$ is a $r$-prox-regular $(r>0)$ if: $\forall s \in U_{r}(C)=$ $\left\{x \in \mathbb{R}^{N} / d_{C}(x)<r\right\}$ has a unique $P_{C}(s)$ in $C$ and the mapping $P_{C}(\cdot)$ is continuous on $U_{r}(C)$.

Definition 2.3. We say that $C$ is r-prox-regular if and only if, for all $\mathrm{x} \in C$, for all $\mathrm{v} \in N^{P}(S, x) \cap \mathbb{B}_{\mathbb{R}^{N}}$ and for every real $\left.\left.t \in\right] 0, r\right]$, we have $x \in P_{C}(x+t v)$.

Proposition 2.4. [17] The set $C$ is $r$-prox-regular if and only if the function $d_{C}^{2}(\cdot)$ is differentiable on $U_{r}(C)$ with a locally Lipschitz derivative and $\nabla d_{C}^{2}(x)=2\left(x-P_{C}(x)\right)$ for all $x \in U_{r}(C)$.

Proposition 2.5. [17] Let $C$ be a prox-regular at $x$. Then

1) $P_{C}(x)$ is single-valued around $\mathrm{x}$.

2) $d_{C}^{2}$ is $C^{1}$ around $\mathrm{x}$.

Lemma 2.6. [17] Let $C$ be a closed set in $\mathbb{R}^{N}$ and take $r>0$. Then the following are equivalent:

(1) $C$ is $r$-prox-regular.

(2) For all $x \in C$ and $\xi \in \mathrm{N}_{C}(x)$ such that $\|\xi\|<r$, we have

$$
x=P_{C}(x+\xi) .
$$

(3) For all $x \in C$ and $\xi \in \mathrm{N}_{C}(x)$, we have

$$
\langle\xi, x-y\rangle \leq \frac{\|\xi\|}{2 r}\|x-y\|^{2}, \forall y \in C .
$$

(4) For all $x, x^{\prime} \in C, \xi \in \mathrm{N}_{C}(x), \xi^{\prime} \in \mathrm{N}_{C}\left(x^{\prime}\right)$ and $\zeta, \xi^{\prime} \in B$ we have

$$
\left\langle\zeta-\xi^{\prime}, x-x^{\prime}\right\rangle \geq-\frac{1}{r}\left\|x-x^{\prime}\right\|^{2} .
$$

One can refer to [19],[4], for further details.

Lemma 2.7. [4] Let $b$ be a postive real number and $f(\cdot), g(\cdot)$ two functions in $L^{1}([0, b], \mathbb{R})$ such that the function $g(\cdot)$ is positive on $[0, b]$, and let $w$ be an absolutely continuous function from $[0, b]$ into $\mathbb{R}^{+}$such that

$$
(1-\lambda) w^{\prime}(t) \leq f(t) w(t)+g(t) w^{\lambda}(t) \text { a.e. } t \in[0, b]
$$


with $0 \leq \lambda<1$. Then the following inequality is satisfied for all $0 \leq t \leq b$

$$
w^{1-\lambda}(t) \leq w^{1-\lambda}(0) \exp \left(\int_{0}^{t} f(\alpha) d \alpha\right)+\int_{0}^{t} \exp \left(\int_{k}^{t} f(\alpha) d \alpha\right) g(s) d s .
$$

Lemma 2.8. [19] If $C \subset \mathbb{R}^{N}$ is a prox-regular subset that the two systems,

$$
\left\{\begin{array}{l}
\dot{y}(t) \in f(y(t))-\mathrm{N}_{C}(y(t)) \text { for almost all } t \in[0,1] \\
y(t) \in C, \forall t \in[0,1] \\
y(0)=x_{0} \in C
\end{array}\right.
$$

and

$$
\left\{\begin{array}{l}
\dot{y}(t)=P_{\overline{c o} T_{C}(y(t))}(f(y(t))) \text { for almost all } t \in[0,1] \\
y(t) \in C, \forall t \in[0,1] \\
y(0)=x_{0} \in C
\end{array}\right.
$$

have the same set of solutions.

\section{Main result}

We give the main result of this section:

\subsection{Assumptions}

Let $C \subset \mathbb{R}^{N}$ be a closed $r$-prox-regular set. We shall also assume, without loss of generality, that $f$ is bounded on $C$, namely, taking into account the Lipshitzianity of $f$, that

$$
\|f(x)\| \leq M, \forall x \in C+r \mathbb{B} .
$$

Theorem 3.1. Let $x(\cdot)$ be a solution of (1.1). Then $\dot{x}(\cdot)$ and $x(\cdot)$ are bounded.

Proof : As $x(\cdot)$ solution of (1.1) we find

$$
\dot{x}(t) \in P_{\overline{c o} \mathrm{~T}_{C}(x(t))}^{f(x(t))} \text { a.e } t \in[0,1],(\text { see, [19]), }
$$

from (1), $\|\dot{x}(t)-f(x(t))\| \leq\|f(x(t))\|$, a.e $t \in[0,1]$ because $0 \in \overline{c o} \mathrm{~T}_{C}(x(t))$.

Since for all $t \in[0,1]$ we have $x(t) \in C$, hence

$$
\|\dot{x}(t)\| \leq 2\|f(x(t))\| \leq 2\|f(x(t))\| \leq 2 M .
$$

Writing $x(t)=x(0)+\int_{0}^{t} \dot{x}(s) d s$, we get

$$
\|x(t)\| \leq 2 M+\left\|x_{0}\right\|,
$$


Theorem 3.2. For every $n \in \mathbb{N}$, there is a unique set of elements $\left\{x_{n}\left(t_{j}\right)\right.$, $\left.t_{0}=0, t_{j+1}=t_{j}+\frac{1}{n}, j=1, \cdots, n\right\}$ satisfies

$$
\left\{\begin{array}{l}
x_{n}\left(t_{j+1}\right) \in \frac{1}{n} f\left(x_{n}\left(t_{j}\right)\right)+P_{C}\left(x_{n}\left(t_{j}\right)\right), j=0, \ldots, n-1, \\
x_{n}(0)=x_{0}
\end{array}\right.
$$

Such that for each $j=0, \cdots, n, x_{n}\left(t_{j}\right) \in U_{\frac{M}{n}}(C)$, has a unique projection on $C$. Moreover, the piecewise extension $x_{n}{ }_{n}^{n}(\cdot)$ of the discrete trajectory $x_{n}\left(t_{j}\right), j=0, \cdots, n$, also satisfies $x_{n}(t) \in U_{\frac{M}{n}}(C)$ a.e $t \in[0,1]$ and $\sup \max \left\{\left\|x_{n}(t)\right\|,\left\|\dot{x}_{n}(t)\right\|\right\} \leq 3 M+\left\|x_{0}\right\|$ for all $t \in[0,1]$. $t \in[0,1]$

Proof : Let $x_{n}\left(t_{j}\right), j=0, \cdots, n$, be a solution of (3.3), there exists some $z_{n}\left(t_{j}\right) \in$ $P_{C}\left(x_{n}\left(t_{j}\right)\right)$ such that

$$
x_{n}\left(t_{j+1}\right)-z_{n}\left(t_{j}\right)=\frac{1}{n}\left(f\left(x_{n}\left(t_{j}\right)\right)\right) .
$$

For sufficiently large $n$ it holds

$$
x_{n}\left(t_{j}\right) \in U_{\frac{M}{n}}(C), \text { for all } j=0, \cdots, n .
$$

Because, (3.4) gives us

$$
d\left(x_{n}\left(t_{1}\right), C\right) \leq\left\|x_{n}\left(t_{1}\right)-x_{0}\right\| \leq \frac{\left\|f\left(x_{0}\right)\right\|}{n} \leq \frac{M}{n},
$$

then $x_{n}\left(t_{1}\right) \in U_{\frac{M}{n}}(C)$, since $\|f(x)\| \leq M, \forall x \in U_{r}(C)$ we can take $\frac{M}{n} \leq r$, and

$$
x_{n}\left(t_{2}\right)-z_{n}\left(t_{1}\right)=\frac{1}{n}\left(f\left(x_{n}\left(t_{1}\right)\right)\right) .
$$

So,

$$
d\left(x_{n}\left(t_{2}\right), C\right) \leq\left\|x_{n}\left(t_{2}\right)-z_{n}\left(t_{1}\right)\right\| \leq \frac{\left\|f\left(x_{n}\left(t_{1}\right)\right)\right\|}{n} \leq \frac{M}{n},
$$

then $x_{n}\left(t_{j-1}\right) \in U_{\frac{M}{n}}(C)$, since $\|f(x)\| \leq M, \forall x \in U_{r}(C)$ we can take $\frac{M}{n} \leq r$, and

$$
x_{n}\left(t_{j}\right)-z_{n}\left(t_{j-1}\right)=\frac{1}{n}\left(f\left(x_{n}\left(t_{j-1}\right)\right)\right) .
$$

So,

$$
d\left(x_{n}\left(t_{j}\right), C\right) \leq\left\|x_{n}\left(t_{j}\right)-z_{n}\left(t_{j-1}\right)\right\| \leq \frac{\left\|f\left(x_{n}\left(t_{j-1}\right)\right)\right\|}{n} \leq \frac{M}{n}
$$

which proves that

from (3.4) we obtain that

$$
x_{n}\left(t_{j}\right) \in U_{\frac{M}{n}}(C),
$$

$$
x_{n}\left(t_{j+1}\right)=\frac{1}{n} f\left(x_{n}\left(t_{j}\right)\right)+P_{C}\left(x_{n}\left(t_{j}\right)\right),
$$

hence, $\left(x_{n}\left(t_{j}\right)\right)_{j=1, \cdots, n}$ is uniquely defined. 
To prove the last assertion of the lemma, we observe that, for every $t \in\left[t_{j}, t_{j+1}\right)$,

$$
\dot{x}_{n}(t)=n\left(x_{n}\left(t_{j+1}\right)-x_{n}\left(t_{j}\right)\right)=f\left(x_{n}\left(t_{j}\right)\right)-n\left(x_{n}\left(t_{j}\right)-P_{C}\left(x_{n}\left(t_{j}\right)\right)\right),
$$

and by using (3.6) we get

$$
\left\|\dot{x}_{n}(t)\right\| \leq 2 M
$$

Thus, writing $x_{n}(t)=x_{n}(0)+\int_{0}^{t} \dot{x}_{n}(s) d s$ and $x_{n}(t)=x_{n}\left(t_{j}\right)+\int_{t_{j}}^{t} \dot{x}_{n}(s) d s$, we get

$$
\left\|x_{n}(t)\right\| \leq 2 M+\left\|x_{0}\right\|
$$

and

$$
d\left(x_{n}(t), C\right) \leq d\left(x_{n}\left(t_{j}\right), C\right)+\frac{2 M}{n} \leq \frac{3 M}{n},
$$

which proves that $x_{n}(t) \in U_{\frac{1}{n}}(C)$, again by an scaling of $n$.

Theorem 3.3. Let $x_{n}(\cdot), n \geq 1$, be as in Theorem $(3.2)$. Then $\left(x_{n}(\cdot)\right)_{n}$ converges uniformally to the unique solution $x(\cdot)$ of $(1.1)$.

Proof : By [11] The system (1.1) has a unique absolutel continuous solution $x(\cdot)$. Then, for all $n$, we write for a.e $t \in\left[t_{j}, t_{j+1}\right)$

$$
\left\langle\dot{x}_{n}(t)-\dot{x}(t), x_{n}(t)-x(t)\right\rangle=\left\langle\dot{x}_{n}\left(t_{j}\right)-\dot{x}(t), x_{n}(t)-x(t)\right\rangle, j=0, \ldots, n-1,
$$

hence,

$$
\begin{aligned}
\left\langle\dot{x}_{n}(t)-\dot{x}(t), x_{n}(t)-x(t)\right\rangle= & \left\langle\dot{x}_{n}\left(t_{j}\right)-\dot{x}(t), x_{n}(t)-x(t)\right\rangle \\
= & \left\langle\dot{x}_{n}\left(t_{j}\right)-\dot{x}\left(t_{j}\right), x_{n}\left(t_{j}\right)-x\left(t_{j}\right)\right\rangle \\
& +\left\langle\dot{x}_{n}\left(t_{j}\right)-\dot{x}\left(t_{j}\right), x\left(t_{j}\right)-x(t)-x_{n}\left(t_{j}\right)+x_{n}(t)\right\rangle \\
& \left.+\left\langle\dot{x}\left(t_{j}\right)-\dot{x}(t)\right), x_{n}(t)-x(t)\right\rangle .
\end{aligned}
$$

To estimate this last inequality, we first observe that there is $\left(w_{n}(\cdot)\right)_{n}$ of simple/step functions defined on $[0,1]$ and converging to $\dot{x}(\cdot)$ in $L^{\infty}\left([0,1], \mathbb{R}^{N}\right)\left(w_{n}(t)\right.$ is constant on $\left[t_{j}, t_{j+1}\right)$ for every $j=0, \ldots, n-1$ ), and since $x(\cdot)$ is bounded by $2 M+\left\|x_{0}\right\|$ (as a consequence of (3.2)) and $\sup _{t \in[0,1]}\|x(t)\| \leq 2 M+\left\|x_{0}\right\|$ (by Lemma 3.2), we get for a.e $t \in\left[t_{j}, t_{j+1}\right), j=0, \ldots, n-1$,

$$
\begin{aligned}
\left.\left\langle\dot{x}\left(t_{j}\right)-\dot{x}(t)\right), x_{n}(t)-x(t)\right\rangle & =\left\langle\dot{x}\left(t_{j}\right)-w_{n}\left(t_{j}\right), x_{n}(t)-x(t)\right\rangle+\left\langle w_{n}(t)-\dot{x}(t), x_{n}(t)-x(t)\right\rangle \\
& \leq 2\left(3 M+2\left\|x_{0}\right\|\right)\left\|\dot{x}-w_{n}\right\|_{\infty}=\mathcal{O}\left(\frac{1}{n}\right),
\end{aligned}
$$

where $\mathcal{O}\left(\frac{1}{n}\right)$ is a value such that $n \mathcal{O}\left(\frac{1}{n}\right)$ is bounded independently of $n$. Also, using (3.2) and (3.9), we have that $\left\|x(t)-x\left(t_{j}\right)\right\| \leq \frac{M}{n}$ and $\left\|x_{n}(t)-x_{n}\left(t_{j}\right)\right\| \leq \frac{M}{n}$ for a.e $t \in\left[t_{j}, t_{j+1}\right)$ and, so,

$$
\left\langle\dot{x}_{n}\left(t_{j}\right)-\dot{x}\left(t_{j}\right), x\left(t_{j}\right)-x(t)-x_{n}\left(t_{j}\right)+x_{n}(t)\right\rangle \leq \mathcal{O}\left(\frac{1}{n}\right) .
$$

On the other hand, using the definition of $\dot{x}_{n}(t)$ (see (3.8) and $\dot{x}(t)$, namely, that $\dot{x}(t)=f(x(t))-y(t)$ for some $y(t) \in \mathrm{N}_{C}(x(t))$, we have for $j=0, \ldots, n-1$

$$
\begin{aligned}
& \left\langle\dot{x}_{n}\left(t_{j}\right)-\dot{x}\left(t_{j}\right), x_{n}\left(t_{j}\right)-x\left(t_{j}\right)\right\rangle \\
& =\left\langle f\left(x_{n}\left(t_{j}\right)\right)-n\left(x_{n}\left(t_{j}\right)-P_{C}\left(x_{n}\left(t_{j}\right)\right)\right), x_{n}\left(t_{j}\right)-x\left(t_{j}\right)\right\rangle \\
& -\left\langle f\left(x_{\mu}\left(t_{j}\right)\right)-y\left(t_{j}\right), x_{n}\left(t_{j}\right)-x\left(t_{j}\right)\right\rangle \\
& =\left\langle f\left(x_{n}\left(t_{j}\right)\right)-f\left(x\left(t_{j}\right)\right), x_{n}\left(t_{j}\right)-x\left(t_{j}\right)\right\rangle \\
& -\left\langle n\left(x_{n}\left(t_{j}\right)-P_{C}\left(x_{n}\left(t_{j}\right)\right)\right)-y\left(t_{j}\right), x_{n}\left(t_{j}\right)-x\left(t_{j}\right)\right\rangle .
\end{aligned}
$$


Since, $n\left(x_{n}\left(t_{j}\right)-P_{C}\left(x_{n}\left(t_{j}\right)\right)\right) \in \mathrm{N}_{C}\left(P_{C}\left(x_{n}\left(t_{j}\right)\right)\right)$, and $y\left(t_{j}\right) \in \mathrm{N}_{C}\left(x\left(t_{j}\right)\right)$, the monotonicity of the operator $\mathrm{N}_{C} \cap \mathbb{B}+\frac{1}{r} \lim i d$, resulting by Proposition 2.7(4), leads us to (recall that $x_{n}\left(t_{j}\right) \in U_{\frac{3 M}{n}}(C)$, by $(3.7)$ ),

$$
\begin{aligned}
& -\left\langle n\left(x_{n}\left(t_{j}\right)-P_{C}\left(x_{n}\left(t_{j}\right)\right)\right)-y(t), x_{n}\left(t_{j}\right)-x\left(t_{j}\right)\right\rangle \\
& =-M\left\langle\frac{n}{M}\left(x_{n}\left(t_{j}\right)-P_{C}\left(x_{n}\left(t_{j}\right)\right)\right)+\frac{1}{r} P_{C}\left(x_{n}\left(t_{j}\right)\right), P_{C}\left(x_{n}\left(t_{j}\right)\right)-x\left(t_{j}\right)\right\rangle \\
& -M\left\langle-\frac{1}{M} y\left(t_{j}\right)-\frac{1}{r} x_{\mu}\left(t_{j}\right), P_{C}\left(x_{n}\left(t_{j}\right)\right)-x\left(t_{j}\right)\right\rangle+\frac{M}{r}\left\|x\left(t_{j}\right)-P_{C}\left(x_{n}\left(t_{j}\right)\right)\right\|^{2} \\
& -\left\langle n\left(x_{n}\left(t_{j}\right)-P_{C}\left(x_{n}\left(t_{j}\right)\right)\right)-y\left(t_{j}\right), x_{n}\left(t_{j}\right)-P_{C}\left(x_{n}\left(t_{j}\right)\right)\right\rangle \\
& \leq \frac{M}{r}\left\|x\left(t_{j}\right)-P_{C}\left(x_{n}\left(t_{j}\right)\right)\right\|^{2} \\
& -\left\langle n\left(x_{n}\left(t_{j}\right)-P_{C}\left(x_{n}\left(t_{j}\right)\right)\right)-y\left(t_{j}\right), x_{n}\left(t_{j}\right)-P_{C}\left(x_{n}\left(t_{j}\right)\right)\right\rangle \\
& \leq \frac{M}{r}\left(2\left\|x\left(t_{j}\right)-x_{n}\left(t_{j}\right)\right\|^{2}+2\left\|x_{n}\left(t_{j}\right)-P_{C}\left(x_{n}\left(t_{j}\right)\right)\right\|^{2}\right)+O\left(\frac{1}{n}\right) \\
& \leq \frac{2 M}{r}\left\|x\left(t_{j}\right)-x_{n}\left(t_{j}\right)\right\|^{2}+O\left(\frac{1}{n}\right) .
\end{aligned}
$$

Finally, the lipschitzianity of $f$ (with a Lipschitz constant $L \geq 0$ ) implies that

$$
\left\langle f\left(x_{n}\left(t_{j}\right)\right)-f\left(x\left(t_{j}\right)\right), x_{n}\left(t_{j}\right)-x\left(t_{j}\right)\right\rangle \leq L\left\|x\left(t_{j}\right)-x_{n}\left(t_{j}\right)\right\|^{2} .
$$

Consequently, by (3.1), (3.14), and (3.15), inequality (3.13) gives us,

$$
\left\langle\dot{x}_{n}\left(t_{j}\right)-\dot{x}\left(t_{j}\right), x_{n}\left(t_{j}\right)-x\left(t_{j}\right)\right\rangle \leq\left(\frac{2 M}{r}+L\right)\left\|x\left(t_{j}\right)-x_{n}\left(t_{j}\right)\right\|^{2}+\mathcal{O}\left(\frac{1}{n}\right) .
$$

Hence, by (3.11), (3.12), and (3.16), inequality (3.10) gives us, for a.e. $t \in\left[t_{j}, t_{j+1}\right)$ and $j=0, \ldots, n-1$,

$$
\left\langle\dot{x}_{n}(t)-\dot{x}(t), x_{n}(t)-x(t)\right\rangle \leq\left(\frac{2 M}{r}+L\right)\left\|x\left(t_{j}\right)-x_{n}\left(t_{j}\right)\right\|^{2}+\mathcal{O}\left(\frac{1}{n}\right) .
$$

But, using (3.2) and (3.9), we have

$$
\begin{aligned}
\left\|x\left(t_{j}\right)-x_{n}\left(t_{j}\right)\right\| & \leq\left\|x(t)-x_{n}(t)\right\|+\left\|x(t)-x\left(t_{j}\right)\right\|+\left\|x_{n}(t)-x_{n}\left(t_{j}\right)\right\| \\
& \leq\left\|x(t)-x_{n}(t)\right\|+\mathcal{O}\left(\frac{1}{n}\right),
\end{aligned}
$$

and, so, (3.17) gives us

$$
\left\langle\dot{x}_{n}(t)-\dot{x}(t), x_{n}(t)-x(t)\right\rangle \leq 2\left(\frac{2 M}{r}+L\right)\left\|x(t)-x_{n}(t)\right\|^{2}+\mathcal{O}\left(\frac{1}{n}\right) .
$$

At this stage, we apply Gronwall's Lemma to obtain

$$
\sup _{t \in[0,1]}\left\|x_{n}(t)-x(t)\right\|^{2} \leq \mathcal{O}\left(\frac{1}{n}\right),
$$

which completes the proof.

\subsection{The basic Theorem}

Theorem 3.4. The differential inclusion (1.1) has a unique absolutel continuous solution $x(\cdot)$, which is the uniform limit of a sequence $\left(x_{n}(\cdot)\right)_{n}$, with $x_{n}(t) \in U_{\frac{M}{n}}(C)$ and has a unique projection on $C$, a.e $t \in[0,1]$. Each $x_{n}(\cdot)$ 
being the piecewise extension of the unique discrete trajectory $x_{n}\left(t_{j}\right), j=0$, $j=0, \cdots, n$ solution of

$$
\left\{\begin{array}{l}
x_{n}\left(t_{j+1}\right)=\frac{1}{n} f\left(x_{n}\left(t_{j}\right)\right)+P_{C}\left(x_{n}\left(t_{j}\right)\right), j=0, \ldots, n-1, \\
x_{n}(0)=x_{0}
\end{array}\right.
$$

Moreover, $\dot{x}_{n}(\cdot) \rightarrow \dot{x}(\cdot)$ weakly in $L^{2}\left([0,1], \mathbb{R}^{N}\right)$ as $n \rightarrow+\infty$.

Proof : By [11] The system (1.1) has a unique absolutel continuous solution, and by Theorem $(3.3),\left(x_{n}(\cdot)\right)_{n}$ converges uniformally to $x(\cdot)$, the unique solution of (1.1). Since $\left(\dot{x}_{n}(\cdot)\right)_{n \geq 1}$ is bounded, we may assume that it weakly converges to some $v(\cdot) \in L^{2}([0,1])$. Classical arguments permit us to show that $v(\cdot)=\dot{x}(\cdot)$.

\subsection{Numerical application}

We can find an approximate solution of the differential inclusion(1.1) by taking $n$ large enough, we have $x_{n}\left(t_{j}\right), j=0, \cdots, n$ is a solution of:

$x_{n}\left(t_{j+1}\right)=\frac{1}{n} f\left(x_{n}\left(t_{j}\right)\right)+P_{C}\left(x_{n}\left(t_{j}\right)\right), j=0, \ldots, n-1$, with $x_{n}(0)=x_{0}$, and $t_{j}:=j h_{n} \in[0,1]$ as $j=0, \ldots, n, h_{n}=\frac{1}{n}$.

So, $x_{n}(0)=x_{0}, x_{1}=x_{n}\left(\frac{1}{n}\right)=\frac{1}{n} f\left(x_{0}\right)+P_{C}\left(x_{0}\right), x_{2}=x_{n}\left(\frac{2}{n}\right)=\frac{1}{n} f\left(x_{1}\right)+$ $P_{C}\left(x_{1}\right) \ldots, x_{j+1}=x_{n}\left(\frac{j}{n}\right)=\frac{1}{n} f\left(x_{j}\right)+P_{C}\left(x_{j}\right) \ldots, x_{n}(1)=\frac{1}{n} f\left(x_{n-1}\right)+P_{C}\left(x_{n-1}\right)$.

And $\left(x_{n}(\cdot)\right)_{n}$ converges uniformally to $x(\cdot)$, the unique solution of $(1.1)$, then for $n$ large enough, the discrete trajectory $x_{n}\left(t_{j}\right), j=0, \cdots, n$ is approximate value of solution to (1.1) in $t_{j}, j=0, \cdots, n$.

We obtain $x_{n}(t)=x_{n}\left(t_{j}\right)-\left(t-t_{j}\right) \dot{x}_{n}\left(t_{j}\right), \forall t \in\left[t_{j}, t_{j+1}[\right.$, as $j=0, \ldots, n$.

So, (3.18) which gives te below equality

$$
\left\|x_{n}(t)-x_{n}\left(t_{j}\right)\right\| \leq \mathcal{O}\left(\frac{1}{n}\right), \forall t \in\left[t_{j}, t_{j+1}[\text {, as } j=0, \ldots, n .\right.
$$

Then $x_{n}(\cdot)$ is an approximate solution to (1.1) for $n$ large enough. 
Differential inclusion with prox-regular set

\section{References}

[1] Aubin, J.P. and Cellina, A.: Differential Inclusions. Set-valued Maps and Viability Theory. Springer-Verlag. Berlin Heidelberg. New York Tokyo, (1984).

[2] Aubin, J. P.and Frankowska, H.: Set-valued Analysis. Birkhauser, Boston. Basal. Berlin, (1990).

[3] B.K. Le.: On a class of Lur'e dynamical systems with state-dependent set-valued feedback. Set-Valued and Variational Analysis. 1-21, (2020).

[4] Beddani, A.: An approximate solution of a differential inclusion with maximal monotone operator. Journal of Taibah University for Science, 14:1, 1475-1481, (2020).

[5] Beddani, A., Sahraoui, R.: Approached Bolza type Problems in Discrete tim. Proceedings of the Jangjeon Mathematical Society, 20 , No. 3. pp. 409-420, (2017).

[6] Beddani, A., Sahraoui, R.: Approximate Optimality Conditions, TWMSJ. App.Eng Math , V.4, No.1, pp. 86-91, (2014).

[7] Bounkhel, M., Castaing, C.: State Dependent Sweeping Process in pUniformly Smooth and q-Uniformly Convex Banach Spaces. Set-Valued Var. Anal 20:187-201, (2012).

[8] Bounkhel, M.: Regularity concepts in nonsmooth analysis. Theory and applications. Springer Optimization and Its Applications, 59. Springer, New York, (2012).

[9] Bounkhel, M.: Existence of solutions for convex sweeping processes in $p$ uniformly smooth and q-uniformly convex Banach spaces. Electron. J. Differential Equations, No. 168, 6pp, (2012).

[10] Clarke, F.: Optimization and Nonsmooth Analysis. Wiley Interscience, New York, (1983).

[11] Edmond, J. F., Thibault, L.: Relaxation of an optimal control problem involving a perturbed sweeping process. Math Prog. Ser. B 104, 347-373, (2005).

[12] Briceno-Arias, L. M., Nguyen, H. D., Peypouquet, J.: Existence, stability and optimality for optimal control problems governed by maximal monotone operators. J. Differential Equations 260, 733-757, (2016).

[13] Mordukhovich, B. S.: Variational Analysis and Generalized Differentiation I. Basic theory. Grundlehren der Mathematischen Wissenschaften, vol. 
330. Springer, Berlin, (2006).

[14] Mordukhovich, B. S.: Variational Analysis and Generalized Differentiation II. Applications. Grundlehren der Mathematischen Wissenschaften, vol. 331. Springer, Berlin, (2006).

[15] Mordukhovich, B. S.: Discrete Approximation and Refined EulerLagrange Condution for Nonconvexe Differential inclusion. Siam J. Control and Optimization Vol. 33, No. 3, pp. 882-915, (1995).

[16] Mordukhovich, B. S., Tian, Y.: Implicit euler approximation and optimization of one sided lipschitzian differential inclusion. Nonlinear analysis and optimization. 165-188, Contemp. Math., 659, Amer. Math. Soc, (2016).

[17] Poliquin, R. A., Rockafellar, R. T., Thibault, L.: Local Differentiability of distance functions. Trans. Amer. Math. Soc., 352, no. 11, 5231-5249, (2000).

[18] Serea, O. S.: Optimality conditions for reflecting boundary control problems Nonlinear. Differ. Equ. Appl. 20, 1225-1242, (2013).

[19] Serea, O. S.: On reflecting boundary problem for optimal control. SIAM J. Control Optim. 42, no. 2, 559-575, (2003).

[20] Sahraoui, R., Thibault, L.: Bolza type problem in discrete time, Taiwanese J. Math., vol.12, No.6, p. 1385-1400, (2008).

[21] Smirnov, G. V.: Introduction to the Theory of Differential Inclusions. American Mathematical Society Providence, Rhode Island. Graduate Studies in Mathematics ISSN 1065-7339, v. 41(2001).

[22] Tzanko, D., Elza, F., Mordukhovich, B. S.: Discrete Approximations, Relaxation, and Optimization of One-Sided Lipschitzian Differential Inclusions in Hilbert Spaces. J. Differential Equations 243, no. 2, 301-328, (2007).

[23] Tolstonogov, A. A.: Differential Inclusions in a Banach Space. Kluwer, Dordrecht, The Netherlands, (2000). 


\section{Supplementary Files}

This is a list of supplementary files associated with this preprint. Click to download.

- LaTeX.rar 